\title{
Efficiency Evaluation of Energy in Northeastern China Based on Data Envelopment Analysis
}

\author{
Hongyan Li $\mathbb{D}^{1},{ }^{1}$ Zhiyu Ma $\mathbb{D}^{1},{ }^{1}$ and Jie Sun $\mathbb{D}^{2}$ \\ ${ }^{1}$ Liaoning Vocational College of Ecological Engineering, Shenyang, China \\ ${ }^{2}$ School of Economics and Management, Beijing Forestry University, Beijing, China \\ Correspondence should be addressed to Hongyan Li; dclihongyan@126.com
}

Received 11 October 2021; Accepted 11 November 2021; Published 6 December 2021

Academic Editor: Maria Alessandra Ragusa

Copyright (c) 2021 Hongyan Li et al. This is an open access article distributed under the Creative Commons Attribution License, which permits unrestricted use, distribution, and reproduction in any medium, provided the original work is properly cited.

The development of the energy economy in Northeastern China is unbalanced. In this paper, some energy structures such as oil, coal, and electricity are chosen as input indexes, while per capita gross domestic product (GDP) and total retail sales of consumer goods are desirable output indexes. The main causes of haze are industrial waste gas emission, industrial wastewater discharge, and solid waste production, which are regarded as undesirable output indexes. Environmental variables include industrial structure, urbanization, per capita GDP, and government planning. The proportion of the tertiary industry's output value to its total output value is one of the important indexes to measure economic development in one area. Therefore, industrial structure plays a vital role in a region's economic development. The tertiary industry oriented by service sector is the main force to promote economic transformation. The development of the urban economy will change from high to low as the process of urbanization, which can be characterized by green coverage of the urban built-up area. The higher per capita GDP, the higher the economic development can be achieved. Government planning refers to the total number of construction projects and completed projects in the year the government takes measures to control pollution. It shows that the total factor productivity of energy green efficiency has been stable in the last decades but fluctuated wildly in special periods, in which technical progress has played a great role, as well as the increase of technical efficiency.

\section{Introduction}

Energy exists everywhere in our life. As a necessary production element, energy drives the advancement of society and human civilization and is essential to support and promote the high-quality development of the regional economy. Energy issues are complex, including regional economic, social, diplomatic, environmental, and security fields. The total amount of economy will affect the demand. When the total production increases, the energy input will increase accordingly, which will further lead to growing consumer demands for energy. China is a vast country with abundant resources, but the differences in resource storage, energy structure, and economic development lead to obvious regional disparity in energy efficiency.

After the strategy of "revitalizing Northeast China" was put forward, it used to revitalize the old industrial base by relying on its rich resources, such as investment-intensive, industrial drive, and capacity expansion. However, the development of heavy industry has led to an increase in fossil fuels, thus generating a large amount of greenhouse gases. The Chinese government issued the "China National Program to Address Climate Change" and announced quantitative action-oriented targets for controlling greenhouse gas emissions in 2009. When China focused on "removing production capacity" in the energy sector in 2016, three resource-based cities in Northeastern China must take the lead in transforming and upgrading. However, many problems exist, especially how to improve energy efficiency in the preponderant industry, to reduce energy consumption and pollution emissions, to optimize the industrial structure, to achieve energy conservation and emission reduction targets led by carbon peak and carbon neutral, and to restore the economy. Therefore, the Northeast region must take environmental protection into account on the basis of comprehensive and balanced development, which is a key 
issue that needs to be addressed by all sectors of society in the coming period and is also an inevitable choice for China's "ecological civilization construction" and the promotion of sustainable development to a high level of green development. In recent years, international and domestic development methods have been closely integrated with green development, and the regional green efficiency is an intuitive evaluation index of green development. Therefore, a more accurate determination of this index will play a key role in guiding the green economic development in a region. Recently, there are a lot of related researches on green efficiency in depth and breadth, which show the following characteristics: (1) Similarity of concepts. Relevant concepts mentioned mostly are: green efficiency, environmental efficiency, and ecological efficiency; sometimes, these three concepts are confused, but after careful analysis, it can be found inheritance and development between them. Under the condition of constant constraint, environmental efficiency emphasizes maximizing economic output and minimizing environmental pollution; ecological efficiency is generally used to measure the development of circular economy, emphasizing energy conservation, emission reduction, and waste recycling [1-3], while green efficiency not only emphasizes maximizing economic output but also takes the level of social development as the desired output, which further realizes green efficiency not only stresses on the maximization of economic output but also takes social development as the desired output, which further realizes the balanced requirement of research in "economic fieldenvironmental field-social field." (2) Diversity of theory application. It involves the integration of economics and geography, taking an effective measurement of efficiency as the basis, and paying attention to the analysis of evolutionary laws and influencing mechanisms of space. There is also the integration of ecology into the measurement of resource environment efficiency, regional environmental and ecological efficiency, and the combination of management, regional economics, ecology, and industrial economics. (3) Similarity of research methods. The research on green efficiency mainly uses data envelopment analysis (DEA) model and its extended model. The goal of the research is urban green development. There are more static analyses and overall evaluation than dynamic and comparative analyses. Therefore, this paper reasonably selects evaluation indexes to measure and analyze green efficiency and its spatial and temporal characteristics of economic development in Northeast China, which not only can improve the theory and method of green efficiency research at home and abroad but also is beneficial to recognize the real situation of green efficiency and is of great significance to improve the economic development of three northeast provinces.

At present, energy efficiency has long been an important issue to the global economic and political theaters. The measurement of energy efficiency is divided into two categories, one is the single-factor energy efficiency index measurement and the other is the total factor energy efficiency measurement, and the methods mainly include parametric and nonparametric. After studying total factor energy efficiency and regional differences in China based on
BCC and Malmquist models, Weng [4] found that there are large differences in energy efficiency in western, central, eastern, and coastal regions of China, and the government should formulate proper energy strategies according to different development status. In "A study on the impact of energy price fluctuations on the energy-environmenteconomy system," Guo and Zhang [5] proposed that the mechanism of energy price fluctuations on the energy-environment-economy system is extremely complex due to the substitution and complementarity between different energy resources and different directions of price fluctuations. In "DEA window analysis and Malmquist index to assess efficiency and productivity in the Spanish electricity sector," Sánchez-Ortiz et al. [6] applied the dea-mulmquist to analyze the efficiency and productivity of the electricity sector, assessing the negative marketing of its overcapacity on the efficiency of distribution companies in the Spanish electricity sector and indicating the importance of proper legislative regulation. Based on the provincial panel data of China from 2007 to 2016, Chai et al. [7] used a slacks-based measure (SBM) model and Malmquist-Luenberger (ML) index to measure the green total factor productivity.

In "Measuring green productivity of country: A generalized metafrontier Malmquist productivity index approach," Lin et al. [8] analyzed environment and productivity in 70 countries from 1981 to 2007 by Malmquist productivity index, using desirable output GDP and undesirable output $\mathrm{CO}_{2}$ to establish functional model. The results show that though developed countries and developing countries use different production technologies, the latter achieve higher environmental output efficiency. $\mathrm{Wu}$ and Zhou [9] used the DEA-Malmquist model to analyze the efficiency of the fiscal expenditure structure and found that the fiscal noted structure has an impact on green growth.

Zhu et al. [10] took three northeastern provinces as the research object and analyzed the relationship among factor input, energy consumption, and economic growth in this region by adopting a long panel and panel causality test model. The results show that there is a long-term equilibrium relationship between economic growth, energy consumption, and input factors in Northeast China. In this case, some measures and suggestions are put forward, such as improving energy efficiency, strengthening energy cooperation, accelerating industrial structure adjustment, and vigorously developing the tertiary industry. Cui and Liu [11] studied the relationship between energy consumption and economic growth in Northeastern China based on empirical analysis of panel data and proposed to develop an intensive development model, increase energy utilization efficiency, increase energy reserve and supply capacity, and vigorously develop the service industry. Ma et al. [12] proposed in "Study on the factors influencing energy consumption in China's industrialization process" that the acceleration of economic development and urbanization is not conducive to the reduction of carbon emissions, and the industrial energy intensity effect, energy structure effect, and industrial structure effect play a suppressive role in the growth of carbon emissions in three northeastern provinces, and the suppressive effect of energy intensity effect is the largest at 
$59 \%$. There is more room for adjustment energy intensity. Reducing energy consumption intensity, adjusting the internal structure, and improving the economic policy system are important means to promote the development of a lowcarbon economy in the three northeastern provinces in the future.

Based on the measurement of energy efficiency, there are some literature that analyze and compare the differences in energy efficiency among regions. Ma et al. [13] proposed in "Measurement of total factor energy efficiency and analysis of influencing factors in three northeastern provinces" that total factor energy efficiency is the highest in Heilongjiang province, followed by Jilin province, and the lowest in Liaoning province; the gap between total factor energy efficiency and total factor productivity is large in some cities; changes in pure technical efficiency and changes in scale efficiency have significant positive effects on energy efficiency in three northeastern provinces, but the impact of technological progress is not significant; the proportion of secondary industry and tertiary industry has a negative impact on energy efficiency, and the structure of industrial ownership has a positive impact. In research on the efficiency of industrial transformation in resource-based cities based on the DEA model, Wang et al. [14] took three prefecture-level resource-based cities in Northeastern China as an example to point out that the development of industrial transformation is unbalanced, but the regional gap is narrowing, and also put forward suggestions for industrial transformation and regional economic development. Scholars have gradually shifted their research focus from single- to full-factor analysis when studying the efficiency of energy and ecology. The SFA model can further explore the effects of input factors, institutions, and natural conditions on the technical efficiency of producers. Therefore, this model can provide a deeper insight into the changing patterns of total factor productivity and the influence of multiple correlation factors on itself. Adopting the SFA model, Xiang [15] evaluated energy efficiency and analyzed its influencing factors by using the GDP value of the region in the current year as output index. Scholars measured single-output efficiency based on the SFA model, but the output of energy activity should not only include desirable output like GDP but also include undesirable output such as ecological environment. If not, the objectivity, comprehensiveness, and validity will be affected. Based on the above analysis, the SFA model divides the actual output into production function, random factors, and technical inefficiency. Considering the impact of technical inefficiency and random disturbance on individual differences, SFA can directly analyze the factors of measured efficiency, but it cannot directly measure multi-output efficiency like DEA. To avoid the shortcomings of the SFA model in measuring efficiency, the projection pursuit model (PP) can be introduced to process the high-dimensional data of energy output by the best projection direction and combine the idea of velocity incentive to construct the PP-SFA dynamic evaluation model, which takes into account the validity of data and comprehensiveness of indexes while adding dynamic time variables and considering the influence of velocity state and velocity trend on the synthetic measurement results. In general, to calculate the energy efficiency of practical problems, most researchers choose clustering analysis, factor analysis, DEA model, and AHP method. However, there are still many problems in the research of energy efficiency. (1) There are many studies on energy efficiency differences based on national and city perspectives but fewer on provincial and municipal perspectives; (2) there are few articles using multiple desirable output indexes for research; (3) there are few studies on the impact of external factors on energy efficiency; and (4) the existing studies on energy efficiency are more overall evaluation but less comparative analysis, more static analysis but less dynamic analysis. Therefore, this paper selects the corresponding evaluation indexes and adopts two-stage DEA to measure and analyze the energy efficiency and its spatial and temporal characteristics in three northeastern provinces, which on the one hand can further improve studies at home and abroad in theory and method and provide theoretical support for the economic development of three northeastern provinces; on the other hand, it is also conducive to recognizing the real situation of energy efficiency, which is significant to develop energy efficiency mode and improve the urban green development.

\section{DEA-Malmquist Method}

The DEA-Malmquist method refers to the analysis of the Malmquist productivity index using the DEA model, which can display more complete characteristics of the selected sample. The Malmquist index includes the pure technical efficiency (PTEC), total factor productivity (TFP), the technical change (TC), the scale efficiency change (SEC), and the technical efficiency change (TEC). The link between these indexes can be expressed as $\mathrm{TFP}=\mathrm{TEC} \times \mathrm{TC}=\mathrm{TC} \times \mathrm{PTEC} \times \mathrm{SEC}$.

In a certain period, $t=1,2, \ldots, T$, the technological production set GRt is the set of all input and output vectors. Namely, $\mathrm{GR}^{t}=\left\{\left(x^{t} t, u^{t}\right): x^{t}\right.$ can produce $\left.u^{t}\right\}$. At the moment, $x^{t} \in R^{\mathrm{Nt}}$ and $u^{t} \in R^{\mathrm{mt}}$. The set of inputs can be defined as $N=\operatorname{maxt}\{\mathrm{Nt}\}$ and the set of outputs as $M=\operatorname{maxt}\{\mathrm{Mt}\}$. The distance function at $t$ is defined as $D_{0}^{t}$; the distance function can interpret the distance between a decision unit and the optimal production point.

$$
D_{0}^{t}\left(x^{t}, u^{t} \mid C, S\right)=\inf \left\{\theta:\left(x^{t}, u^{t} / \theta\right) \varepsilon\left(\mathrm{GR}^{t} \mid C, S\right)\right\} .
$$

To define the Malmquist index, another distance function for different periods is shown below:

$$
D_{0}^{t}\left(x^{t+1}, u^{t+1} \mid C, S\right)=\inf \left\{\theta:\left(x^{t+1}, u^{t+1} / \theta\right) \varepsilon\left(\mathrm{GR}^{t} \mid C, S\right)\right\} .
$$

Xiong [16] indicated that this function describes how much $\left(x^{t+1}, u^{t+1}\right)$ can be produced at the technical level at $t$. This can also be defined as the ratio of actual output to optimal output. Similarly, the opposite of the distance function $D_{0}^{t+1}\left(x^{t}, u^{t}\right)$ describes how much $\left(x^{t}, u^{t}\right)$ can be produced at the technical level at $t+1$. To avoid controversy, the Malmquist index is defined as the geometric mean of two 
distance functions. Therefore, under the assumption of fixed scale returns, the mathematical expression of the Malmquist index is as follows:

$$
M^{t+1}\left(u^{t+1}, x^{t+1}, u^{t}, x^{t}\right)=\left[\frac{D_{0}^{t+1}\left(u^{t+1}, x^{t+1} \mid \mathrm{CRS}\right)}{D_{0}^{t+1}\left(u^{t}, x^{t} \mid \mathrm{CRS}\right)} \times \frac{D_{0}^{t}\left(u^{t+1}, x^{t+1} \mid \mathrm{CRS}\right)}{D_{0}^{t}\left(u^{t}, x^{t} \mid \mathrm{CRS}\right)}\right] .
$$

$M>1$ means rising productivity; $M=1$ means constant productivity; and $M<1$ means falling productivity.
According to Fare et al. [17], function (3) can be rewritten as follows:

$$
M^{t+1}\left(u^{t+1}, x^{t+1}, u^{t}, x^{t}\right)=\frac{D_{0}^{t+1}\left(u^{t+1}, x^{t+1} \mid \mathrm{CRS}\right)}{D_{0}^{t}\left(u^{t}, x^{t} \mid \mathrm{CRS}\right)}\left[\frac{D_{0}^{t}\left(u^{t+1}, x^{t+1} \mid \mathrm{CRS}\right)}{D_{0}^{t+1}\left(u^{t+1}, x x^{t+1} \mid \mathrm{CRS}\right)} \times \frac{D_{0}^{t}\left(u^{t}, x^{t} \mid \mathrm{CRS}\right)}{D_{0}^{t+1}\left(u^{t}, x^{t} \mid \mathrm{CRS}\right)}\right]^{1 / 2},
$$

where $\quad\left[D_{0}^{t}\left(u^{t+1}, x^{t+1} \mid \mathrm{CRS}\right) / D_{0}^{t+1}\left(u^{t+1}, x x^{t+1} \mid \mathrm{CRS}\right)\right.$ $\left.\times D_{0}^{t}\left(u^{t}, x^{t} \mid \mathrm{CRS}\right) / D_{0}^{t+1}\left(u^{t}, x^{t} \mid \mathrm{CRS}\right)\right]^{1 / 2}$ represents the extent to which the production frontier changes over time and can measure the technical change (TC), with TC $>1$ representing technical progress and TC $<1$ representing technical regression. The ratio of $D_{0}^{t+1}\left(u^{t+1}, x^{t+1} \mid \mathrm{CRS}\right) / D_{0}^{t}\left(u^{t}, x^{t} \mid \mathrm{CRS}\right)$ represents the horizontal distance of the actual output from the production frontier, so it can measure the technical efficiency change (TEC), with TEC $>1$ representing technical efficiency improvement and TEC $<1$ representing technical efficiency deterioration.

\section{Methods and Materials}

3.1. Study Area Selection. The State Council has identified 69 resource-depleted cities (counties or districts) in three batches since 2008. Under the strategic background of revitalizing Northeast China, this study focuses on Liaoning, which has the largest number of resource-depleted cities. Liaoning province is an old industrial base in China, with long cold winter and short warm summer. In recent years, the haze in Liaoning has been serious due to unreasonable energy utilization efficiency. Therefore, this paper selects six cities with resource depletion problems in Liaoning province as the research area, which are Anshan, Fushun, Benxi, Fuxin, Panjin, and Huludao.

3.2. Data Source. The analysis of energy should be supported by more extensive panel data. Based on the comprehensiveness and accuracy of data, this paper selects relevant input and output data of the research area in the past decade.

The data are from Liaoning Statistical Yearbook and China Energy Statistical Yearbook. Some of the data that are not directly available are supplemented by interpolation from the statistical bulletin of national economic and social development and the statistical yearbook of each municipality. Some data that cannot be obtained by interpolation method can be calculated by "epitaxial method" or "averaging method" combined with practical investigation results.
3.3. Variable Selection. Energy efficiency refers to the degree to which the actual energy input achieves the optimal level or the maximum actual output when the energy input is certain.

Environmental efficiency is measured by the maximization of economic output and the minimization of environmental pollution.

Ecological efficiency is mostly used to measure regional circular economic development. It not only reflects the requirements of energy conservation and emission reduction but also emphasizes waste recycling. The selection of indexes is limited to the economic and environmental systems.

While green efficiency considers increasing economic output to the maximum, as well as improving social development to a certain extent. Meanwhile, the focus covers three major fields of economy, environment, and society, which is also the requirement and manifestation of balanced green development.

Based on the above analysis, the desirable output indexes are set as per capita GDP and total retail sales of consumer goods, which can show the economic and social development of three northeastern provinces as well as the economic condition and consumption demand indexes of the residents in this region so as to achieve the triple win of "economy-society-ecology." Evaluation of energy ecoefficiency to achieve balanced development between socio-economic construction and ecological civilization has become the focus of current research. On the contrary, the undesirable output is the main cause of haze in Liaoning, that is, industrial waste gas emissions, industrial wastewater discharge, and solid waste production. Energy structure index is selected as input index, namely synthetic energy consumption and industrial electricity consumption. The indicators used in the study are shown in Table 1.

\section{Results}

In order to systematically study the application of energy efficiency in Liaoning Province, this paper puts the relevant 
TABLe 1: Index system.

\begin{tabular}{lcc}
\hline $\begin{array}{l}\text { Input/output } \\
\text { Input index }\end{array}$ & $\begin{array}{c}\text { Categories of index } \\
\text { Oil, coal, and other consumption } \\
\text { Industrial consumption of electricity }\end{array}$ & $\begin{array}{c}\text { Name of index } \\
\text { Synthetic energy consumption } \\
\text { Electricity consumption }\end{array}$ \\
\hline Output index & Desirable output & $\begin{array}{c}\text { Per capita GDP } \\
\text { Total retail sales of consumer goods } \\
\text { Industrial waste gas emission } \\
\text { Industrial wastewater discharge } \\
\text { Industrial solid waste production }\end{array}$ \\
\hline
\end{tabular}

panel data of sample cities from 2009 to 2018 into DEA operation system DEAP and obtains multiple indexes of energy efficiency in six cities.

4.1. Total Factor Productivity. A system is composed of several elements. Considering an enterprise as a system, the real productivity of its elements such as structural upgrading, product quality optimization, production technology improvement, and enterprise management model optimization constitutes the total factor productivity. In short, total factor productivity is the combined productivity of all elements in the system, which can be called system productivity. Analyzed from the perspective of energy efficiency, the total factor productivity index of a region will increase when the overall energy efficiency is improved. The specific values of total factor productivity changes in cities can be obtained by collating data in DEAP, as shown in Table 2.

Table 2 shows the change of total factor productivity of energy in Liaoning Province from 2008 to 2017. An index greater than 1 represents productivity improvement. The change of total factor productivity in sample cities of Liaoning Province showed negative growth from 2010 to 2011 , with negative growth rates of $-12 \%,-30 \%,-66 \%$, $-88 \%$, and $14 \%$, respectively. Among them, the negative growth rate of Fuxin reached the maximum of $-88 \%$. The overall situation was stable from 2011 to 2015, and each city kept a higher growth rate from 2015 to 2016, with Benxi having a larger increase reaching $47.4 \%$.

Figure 1 shows the overall trend of total factor efficiency changes in the past 10 years. This paper argues that the overall decline of the TFP index in 2010-2011 is related to the policy of the new energy industry into the strategic emerging industry during this period. The efficiency improvement from 2015 to 2016 was influenced by Liaoning's energy planning and policies for emerging industries, showing a good overall trend.

4.2. Technical Change Index. In terms of the technical change index in Table 3, TC $>1$ accounts for more than $\mathrm{TC}<1$, that is, the proportion of a technical progress is more than that of technical recession. Panjin and Fuxin are the sample cities with more technical recession. In terms of the period, 2010-2011 was generally manifested as the decline of technology, among which Fuxin's technology decline was relatively large, with the decline rate reaching $65 \%$. The analysis of this paper has a certain relationship with the adjustment of energy strategy in that year. The obvious periods of technical decline are 2010-2011 and 2013-2014, with six and five cities showing technical recession respectively, and no more than two cities in other periods.

Figure 2 shows the average technical variation in sample cities. In the observation period, the average annual technical change rates are positive, indicating that technology is innovative overall. Among them, Fuxin's annual average technical progress is the highest at 1.148, while other cities are between 1.07 and 1.09. According to the investigation of the local energy department, since the adjustment of the national energy strategy in 2011, Fuxin issued several policies to make a comprehensive adjustment to energy utilization, especially in the use of green energy, the results of which can be clearly reflected in technical changes.

4.3. Technical Efficiency Change Index. TEC represents the change of relative efficiency under the condition of constant return to scale and free disposal of elements. It measures the degree of catch-up of the production system to production possibility frontier from stage $t$ to stage $t+1$. If TEC $>1$, it indicates that technical efficiency has improved; otherwise, technical efficiency has decreased. Specific values are shown in Table 4.

From the analysis of efficiency changes, the technical efficiency of Panjin and Huludao is stable, and that of Fushun is also stable at 1 after 2010. Anshan, Benxi, and Fuxin fluctuated greatly, and the maximum decrease of technical efficiency was more than $40 \%$.

By comparing the technical progress index analysis in the same period, the main factors for productivity change in each year of sample cities can be found. Taking Panjin and Huludao as an example, the annual average change of technical progress is $7.7 \%$ and $7.3 \%$, and the change of technical efficiency is 0 . Then it is concluded that the main reason of productivity change in the study period is the change of technical progress. Therefore, it can be concluded that the annual average change in technical progress and technical efficiency are $9.3 \%$ and $3.5 \%$, respectively, indicating that the impact of technical change on synthetic energy utilization is more significant.

4.4. Pure Technical Efficiency. Efficiency changes can be further decomposed into pure technical efficiency changes and scale efficiency changes. As shown in Table 5, the pure technical efficiency changes of Anshan, Benxi, and Panjin were all 1 , which means that there was no change in relative full technical efficiency. 


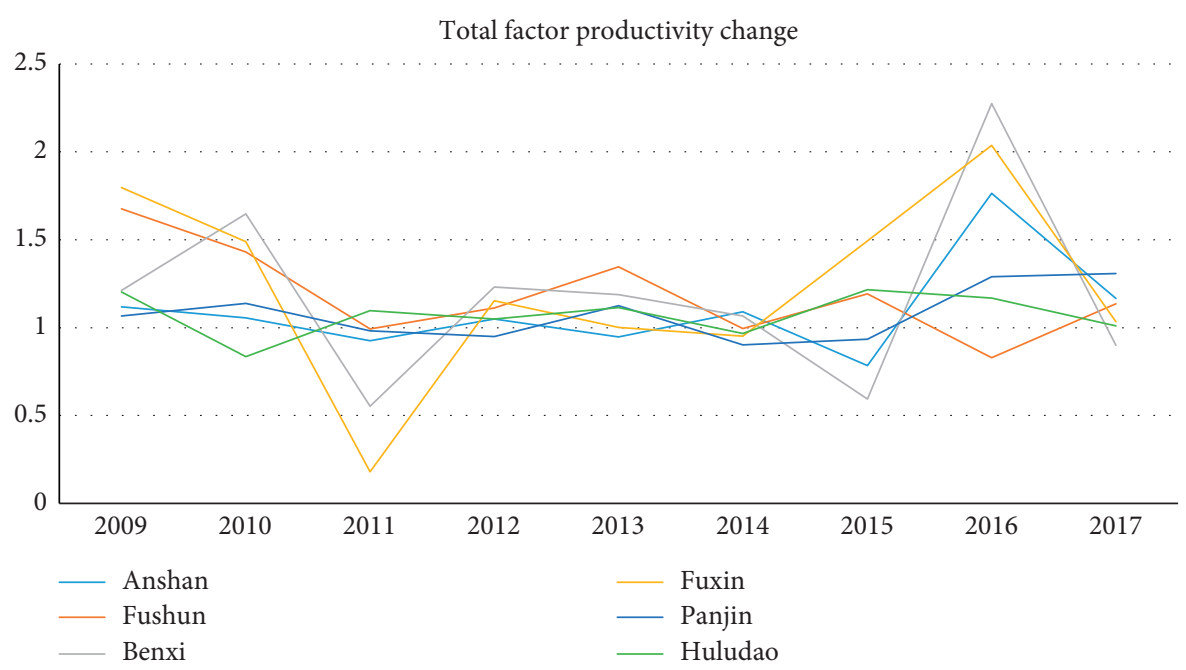

FIgURE 1: Total factor productivity change.

TABLE 2: Changes in urban total factor productivity.

\begin{tabular}{lcccccc}
\hline & Anshan & Fushun & Benxi & Fuxin & Panjin & Huludao \\
\hline $2008-2009$ & 1.119 & 1.676 & 1.211 & 1.797 & 1.066 & 1.202 \\
$2009-2010$ & 1.056 & 1.43 & 1.647 & 0.18 & 0.835 \\
$2010-2011$ & 0.926 & 0.992 & 0.553 & 1.153 & 1.981 & 0.95 \\
$2011-2012$ & 1.048 & 1.111 & 1.231 & 1.002 & 1.124 & 1.049 \\
$2012-2013$ & 0.948 & 1.345 & 1.187 & 0.951 & 1.902 \\
$2013-2014$ & 1.09 & 0.995 & 0.593 & 2.037 & 0.934 & 1.289 \\
$2014-2015$ & 0.784 & 1.192 & 2.275 & 1.033 & 1.308 \\
$2015-2016$ & 1.764 & 0.829 & 0.899 & & 1.216 \\
$2016-2017$ & 1.166 & 1.135 & & 1.009 \\
\hline
\end{tabular}

TABLE 3: Changes in urban technical change.

\begin{tabular}{|c|c|c|c|c|c|c|}
\hline & Anshan & Fushun & Benxi & Fuxin & Panjin & Huludao \\
\hline 2008-2009 & 1.119 & 1.067 & 1.225 & 1.797 & 1.066 & 1.202 \\
\hline 2009-2010 & 1.143 & 1.119 & 1.326 & 1.489 & 1.139 & 0.835 \\
\hline $2010-2011$ & 0.856 & 0.988 & 0.553 & 0.349 & 0.981 & 1.097 \\
\hline 2011-2012 & 1.048 & 1.111 & 1.231 & 0.964 & 0.95 & 1.049 \\
\hline $2012-2013$ & 1.131 & 1.345 & 1.187 & 1.162 & 1.124 & 1.114 \\
\hline 2013-2014 & 0.924 & 0.995 & 1.066 & 0.915 & 0.902 & 0.967 \\
\hline 2014-2015 & 1.184 & 1.192 & 1.013 & 1.13 & 0.934 & 1.216 \\
\hline 2015-2016 & 1.156 & 0.829 & 1.332 & 1.492 & 1.289 & 1.169 \\
\hline $2016-2017$ & 1.166 & 1.135 & 0.899 & 1.033 & 1.308 & 1.009 \\
\hline
\end{tabular}

The pure technical efficiency change in Fushun was in a state of change from 2008 to 2010, and after 2010, the pure technical efficiency change has been 1 with no change. The highest rate of change during the observation period was $65.5 \%$ in the period 2013-2015, which was related to the policy formulation of green energy-related industries in the Fuxin region as mentioned earlier.

4.5. Scale Efficiency Change. The scale efficiency measures the ratio between the margin of production with constant returns to scale and the margin of production with variable returns to scale. The scale is efficient when the scale efficiency is 1 , and the payoff to scale is constant at that time.

Table 6 shows that Panjin and Huludao maintained the optimal scale during the observation period because the scale efficiency variation value was 1 . Combining the specific values, we can analyze that Anshan, Fushun, Benxi, and Fuxin had a large-scale variation during the study period, and Anshan and Benxi had similar data performance during this period, which was related to the construction of quality management and service system of the energy system and a series of policies introduced by Liaoning Province in 2008.

From the comparison of the average scale efficiency in Figure 3, the deviation from the optimal scale in Fushun was larger, with the highest improvement value of $59.5 \%$ in 2008-2009. Through policy research, it was found that Fushun Municipal People's Government issued the "Notice of the General Office of Fushun Municipal People's Government on the Issuance of Fushun Rural Energy Management Measures" in 2007, which clearly proposed to encourage the use of clean energy and gave the industry 


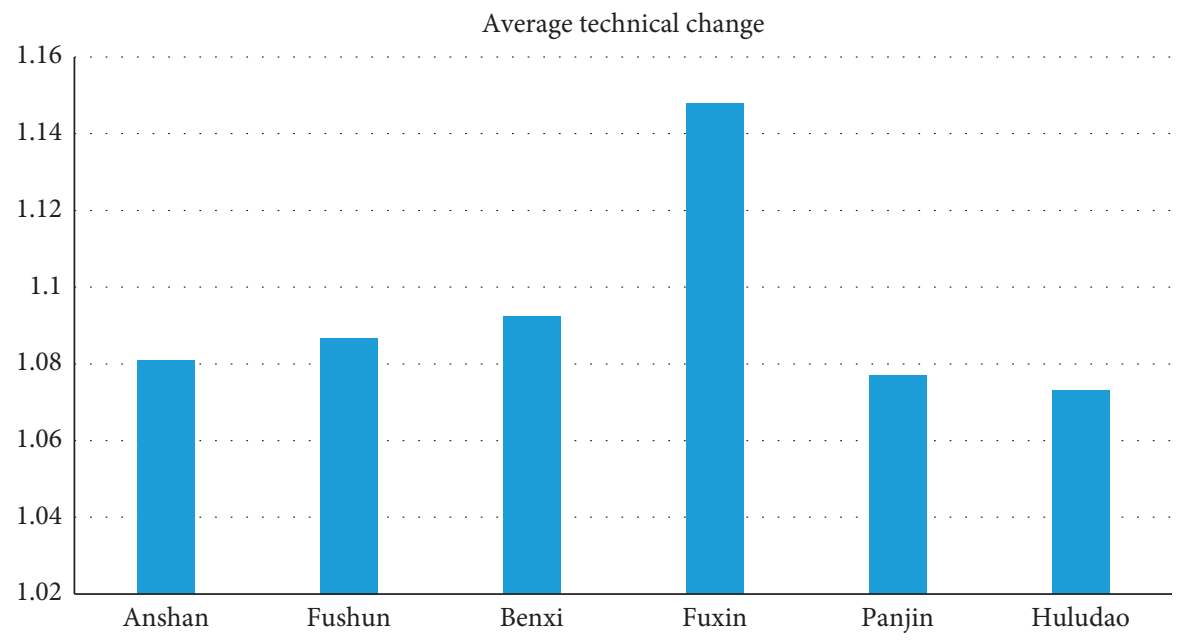

Figure 2: Average technical change.

TABle 4: Changes in urban technical efficiency.

\begin{tabular}{lcccccc}
\hline & Anshan & Fushun & Benxi & Fuxin & Panjin & Huludao \\
\hline $2008-2009$ & 1 & 1.572 & 0.988 & 1 & 1 & 1 \\
$2009-2010$ & 0.924 & 1.277 & 1.242 & 1 & 0.517 & 1 \\
$2010-2011$ & 1.083 & 1.004 & 1 & 1.195 & 1 & 1 \\
$2011-2012$ & 1 & 1 & 1 & 0.862 & 1 \\
$2012-2013$ & 0.839 & 1 & 1 & 1.04 & 1 \\
$2013-2014$ & 1.179 & 1 & 0.586 & 1.321 & 1 \\
$2014-2015$ & 0.662 & 1 & 1.708 & 1.365 & 1 \\
$2015-2016$ & 1.526 & 1 & 1 & 1 & 1 \\
$2016-2017$ & 1 & & & & 1 \\
\hline
\end{tabular}

TABle 5: Changes in pure technical efficiency.

\begin{tabular}{|c|c|c|c|c|c|c|}
\hline & Anshan & Fushun & Benxi & Fuxin & Panjin & Huludao \\
\hline 2008-2009 & 1 & 0.985 & 1 & 1 & 1 & 1 \\
\hline 2009-2010 & 1 & 1.015 & 1 & 1 & 1 & 1 \\
\hline 2010-2011 & 1 & 1 & 1 & 0.702 & 1 & 1 \\
\hline 2011-2012 & 1 & 1 & 1 & 0.924 & 1 & 1 \\
\hline 2012-2013 & 1 & 1 & 1 & 1.125 & 1 & 1 \\
\hline 2013-2014 & 1 & 1 & 1 & 0.908 & 1 & 1 \\
\hline 2014-2015 & 1 & 1 & 1 & 1.503 & 1 & 1 \\
\hline 2015-2016 & 1 & 1 & 1 & 1.004 & 1 & 1 \\
\hline 2016-2017 & 1 & 1 & 1 & 1 & 1 & 1 \\
\hline
\end{tabular}

TABLE 6: Changes in scale efficiency.

\begin{tabular}{lcccccc}
\hline & Anshan & Fushun & Benxi & Fuxin & Panjin & Huludao \\
\hline $2008-2009$ & 1 & 1.595 & 0.988 & 1 & 1 & 1 \\
$2009-2010$ & 0.924 & 1.259 & 1.242 & 1 & 0.737 & 1 \\
$2010-2011$ & 1.083 & 1.004 & 1 & 1.293 & 1 & 1 \\
$2011-2012$ & 1 & 1 & 1 & 0.766 & 1 & 1 \\
$2012-2013$ & 0.839 & 1 & 1 & 1.146 & 1 & 1 \\
$2013-2014$ & 1.179 & 1 & 0.586 & 1.36 & 1 \\
$2014-2015$ & 0.662 & 1 & 1.708 & 1 & 1 \\
$2015-2016$ & 1.526 & 1 & 1 & 1 & 1 \\
$2016-2017$ & 1 & & & & 1 \\
\hline
\end{tabular}

management regulations and professional technical standards for the construction of energy utilization projects.

Meanwhile, the total comprehensive energy consumption of industries above the scale in Fushun city in 2012 increased by $4 \%$ year-on-year, but the consumption of raw coal, coke, gasoline, kerosene, and other refined products decreased by more than $6.5 \%$ year-on-year, and more than $70 \%$ of the energy used by enterprises became "secondary energy conversion" consumption, which greatly improved the green efficiency and reduced the non-expected output. 


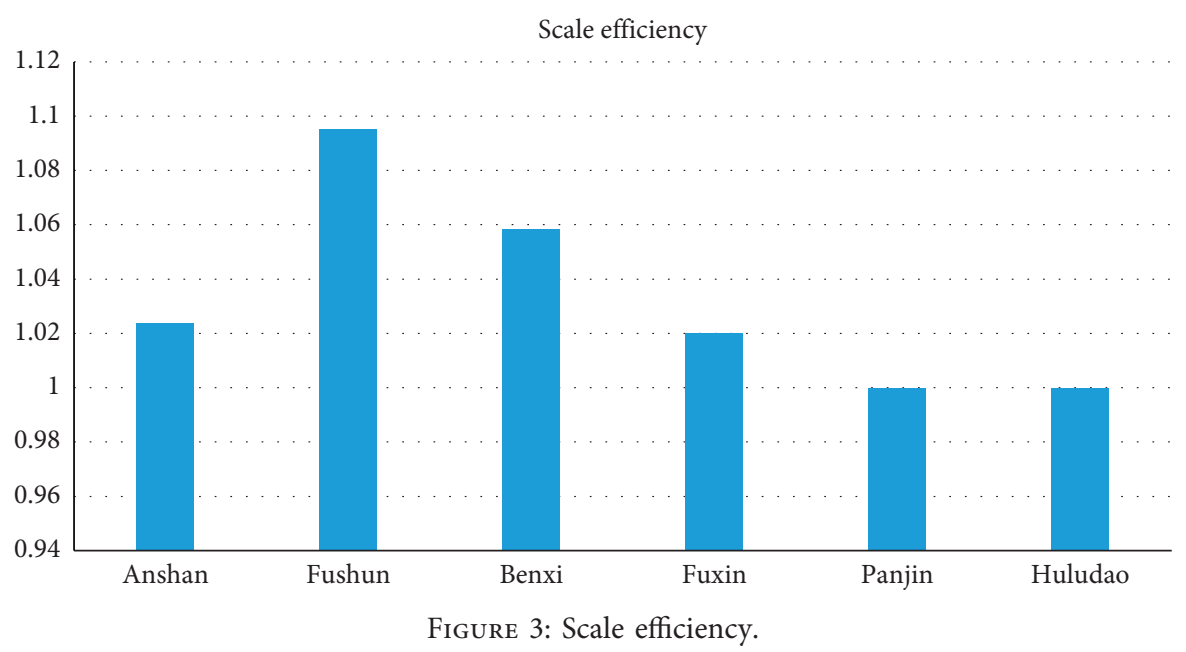

Therefore, it can be seen that Fushun, as an energy-depleted city, was in the transition stage of energy consumption during this period, replacing traditional coal and oil resources with more clean energy and renewable energy consumption to ensure sustainable development of enterprises.

\section{Conclusion}

After the 11th Five-Year Plan, China's energy policy has been reformed in a more detailed and systematic way, especially after the white paper China's Energy Policy released by the State Council Information Office in October 2010, which mentioned that maintaining the longterm stable and sustainable use of energy resources is an important strategic task. Relevant departments at all levels in China have actively adjusted the deployment of the energy industry and formulated a series of practical policies for green energy utilization. Energy productivity of the sample cities in Liaoning Province from 2010 to 2012 has changed significantly, and these changes are inextricably linked to the adjustment of strategies and the formulation of policies.

Meanwhile, from the above analysis, the energy efficiency changes in Fuxin are mainly driven by technical progress, while in other cities are influenced by both technical progress and technical efficiency to some extent, and no selected cities are entirely driven by technical efficiency changes. In turn, technical progress has played a significant role in driving the energy efficiency progress in Liaoning Province in all sample cities. This is also proof of continuous exploration and improvement of green energy use in Liaoning Province in the past decade. Only by breaking the inherent limitations and creating new forms of energy use can greater technical progress be achieved.

To sum up, suggestions given in this paper are as follows: first, to strengthen policy support for green energy efficiency and establish a sound and thorough energy management and evaluation system and second, to improve energy technology, and improving energy efficiency through technical reform is a crucial process.

\section{Data Availability}

The panel statistics data used to support the findings of this study are available from the corresponding author upon request.

\section{Conflicts of Interest}

The authors declare that they have no conflicts of interest.

\section{References}

[1] Z. Li, P. Li, and G. Li, "Regional disparity of urban energy efficiency and its impact factors in China," in Proceedings of the 2nd International Postgraduate Conference on Infrastructure and Environment, IPCIE, pp. 460-466, Kuala Lumpur, 2010.

[2] A. Duro, V. Piccione, M. A. Ragusa, and V. Veneziano, New Enviromentally Sensitive Patch Index-ESPI-For MEDALUS ProtocolAmerican Institute of Physics, College Park, Maryland, US, 2014.

[3] L. Luo and S. Liang, "Study on the efficiency and regional disparity of green technology innovation in China's industrial companies," Chinese Journal of Population Resources and Environment, vol. 14, no. 4, pp. 262-270, 2016.

[4] F. Weng, "Characteristics of China's energy structure and development prospects," Economic Perspectives, no. 01, pp. 90-92, 2012.

[5] Z. Guo, X. Zhang, and Y. Zheng, "A study on the impact of energy price fluctuations on the energy-environment-economy system," China Management Science, vol. 11, pp. 22-30, 2018.

[6] J. Sánchez-Ortiz, T. Garcia-Valderrama, V. Rodríguez-Cornejo, and F. Cabrera-Monroy, "DEA window analysis and Malmquist index to assess efficiency and productivity in the Spanish electricity sector," International Journal of Energy Sector Management, vol. 4, 2021.

[7] B. Chai, J. Gao, L. Pan, and Y. Chen, "Research on the impact factors of green economy of China-from the perspective of system and foreign direct investment," Sustainability, vol. 13, no. 16, p. 8741, 2021.

[8] E. Y.-Y. Lin, P.-Y. Chen, and C.-C. Chen, "Measuring green productivity of country: a generalized metafrontier Malmquist 
productivity index approach," Energy, vol. 55, pp. 340-353, 2013.

[9] Y. Wu and X. Zhou, "Research on the efficiency of China's fiscal expenditure structure under the goal of inclusive green growth," Sustainability, vol. 13, no. 17, p. 9725, 2021.

[10] T. Zhu, Y. Song, and L. Song, "Study on the relationship between energy consumption, factor inputs and economic growth in three northeastern provinces-based on long panel and panel causality test models," Economic Economics, no. 04, pp. 13-18, 2015.

[11] M. Cui and C. Liu, "Research on the relationship between energy consumption and economic growth in three northeastern provinces - an empirical analysis based on panel data," Journal of North China Electric Power University, no. 01, pp. 1-8, 2016.

[12] X. Ma, B. Dong, Y. Yu, C. Wang, and Q. Yang, "Measurement of carbon emissions from energy consumption and influencing factors in three northeastern provinces," China Environmental Science, vol. 38, no. 08, pp. 3170-3179, 2018.

[13] X. Guo, Study on the factors influencing energy consumption in China's industrialization process, Master's thesis, Harbin Institute of Technology, Harbin, China, 2018.

[14] A. Wang, Y. Yang, and J. Yang, "The GPM $(1,1, \mathrm{~m})$ model and its application to energy consumption forecasting in China," Mathematical Practice and Understanding, vol. 51, no. 02, pp. 104-112, 2021.

[15] W. Xiang and X. Zhou, "Green total factor productivity estimation in Zhejiang province - based on DEA-Malmquist index method," Science and Technology and Economics, no. 06, pp. 61-65, 2019.

[16] L. Xiong, A Study on the Efficiency of Life Insurance Companies in China Based on DEA-Malmquist Index Method, Master's thesis, Guangdong Business School, Guangzhou, China, 2012.

[17] R. Fare, S. Grosskopf, M. Norris, and Z. Zhang, "Productivity growth, technical progress, and efficiency change in industrialized countries," American Economic Review, vol. 84, no. 1, pp. 66-83, 1994. 